\title{
Nachruf auf Prof. Hermann Schmitz - Begründer der Neuen Phänomenologie
}

\author{
16.05.1928-05.05.2021
}

\begin{abstract}
"Wie wir in der Welt sind"
„Wenn ich vom Leib spreche, dann meine ich nicht den menschlichen Körper, den wir betasten und über unsere fünf Sinne wahrnehmen können, sondern all die Regungen, die wir in dessen Gegend spüren. Beispielsweise Hunger, Lust, Angst oder Frische" [1].

Zum Wintersemester 1990/1991 nach Kiel berufen, im Gepäck ein Manuskript zur Körpergeschichte Chinas, traf ich Hermann Schmitz und auf die Neue Phänomenologie [2]. Das Manuskript versank in der Schublade. Ich begann von vorn.

Von jeher war die chinesische Philosophie mehr am gespürten Leib interessiert als am tast- und sichtbaren Körper und immer waren Übersetzungen in ein vom Körper-Geist-Dualismus geprägtes Denken und Sprechen von Unbehagen begleitet: Die Lebenskraft $Q i$ ist ein Spürphänomen und altchinesisches Denken archaische Leibphilosophie.
\end{abstract}

Der Umgang mit leiblichen Regungen und Emotionen mag verschieden sein von Kultur zu Kultur, von Epoche zu Epoche, auf einer tieferen Stufe des Erlebens aber kommen die Menschen überein: Auch in China "hüpft" nicht nur „das Herz vor Freude", die ganze Person ist davon erfasst. Wie Freude sucht Zorn die Weite, wenn dem Zornigen „die Kappe anschwillt". Umgekehrt bringen Metaphern für Angst oder Scham leibliche Enge zum Ausdruck.

Lassen wir Hermann Schmitz zu Wort kommen auf die Frage, worin der lebenspraktische Nutzen der Neuen Phänomenologie besteht. Das mag an diesem Ort bedeuten, offene Türen einzurennen, dürften Leser:innen der DZA sehr wohl

Deutsche Zeitschrift für Akupunktur

$2021 \cdot 64$ (3): 241

https://doi.org/10.1007/s42212-021-00395-4

Angenommen: 9. Juni 2021

Online publiziert: 13. Juli 2021

(c) Springer Medizin Verlag GmbH, ein Teil von

Springer Nature 2021 wissen, warum sie „komplementär“ zugreifen auf die Traditionelle Chinesische Medizin (TCM):

„Ich bin kein Prophet, der ins Leben eingreift, die Fahne hochhält und die Leute weiterführt. Es gibt aber eine ganze Reihe von Wissenschaften, die eine phänomenologische Kur verdient hätten, zum Beispiel die Medizin und die Psychologie. Beide Wissenschaften berufen sich vor allem auf die vorher schon angesprochenen, objektiven Tatsachen'. Sie interessieren sich also meistens nur für die physiologischen Grundlagen von Krankheitsbildern. Verloren geht dadurch die Aufmerksamkeit für das Erleben der Patienten. Schmerz ist zum Beispiel nicht gleich Schmerz. Er kann stechen, pochen, ziehen, drücken, schwelen und noch viel mehr. Man muss schon genau sagen, was man meint, wenn man ein Wort wie Schmerz gebraucht. In der klinischen Praxis herrscht demgegenüber ein Mangel an begrifflicher Differenzierung und an Einfühlung in die Situation der Patienten. Dadurch verengt sich auch der Blick für therapeutische Möglichkeiten. Es freut mich deshalb sehr, dass es heute einige Wissenschaftler und Wissenschaftlerinnen ... gibt, die meinen Ansatz für ihre Forschung nutzen und weiterentwickeln" [1].

Auch wer selektiv aus dem „unerschöpflichen Gegenstand“ der Neuen Phänomenologie schöpft, dem bleibt nicht verborgen, wie geschmeidig und zugleich stringent ihre Begriffe und Konzepte sind, die sich auf alle Bereiche der Philosophie erstrecken: von Anthropologie und Erkenntnistheorie über das Göttliche, alle möglichen Künste, inklusive Architektur und Dichtkunst, bis hin zur Ethik.

Diese groß angelegte Theorie, die das „wirkliche Leben“ aus dem Leib heraus begreifbar machen will, und der Mut, Mitte des 20. Jahrhunderts ein System der Philosophie vorzulegen, immer wieder zu ergänzen und daran zu feilen, verdienen Bewunderung und Dankbarkeit.
Vielleicht gibt es eine Phänomenologie des Sterbens, aber keine des Todes. Wir wissen nicht, wie es sich anfühlt, in der "großen Weite“ (Jù-shì 巨室) zu sein jenseits der „weißen Wolken“ (Bái-yún 白云). Dahin geht jetzt mein „spürender Blick“.

\section{Gudula Linck, Freiburg im Mai 2021}

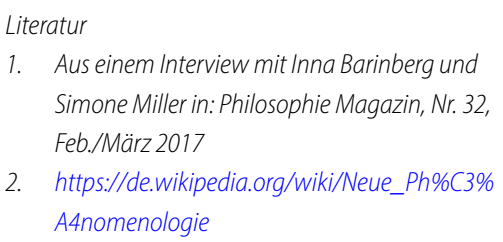

1. Aus einem Interview mit Inna Barinberg und Simone Miller in: Philosophie Magazin, Nr. 32, Feb./März 2017

2. https://de.wikipedia.org/wiki/Neue_Ph\%c3\% A4nomenologie

\section{Anmerkung der Redaktion}

Wenn Hermann Schmitz sagte, "dass es heute einige Wissenschaftler und Wissenschaftlerinnen ... gibt, die meinen Ansatz für ihre Forschung nutzen und weiterentwickeln," dann hat er sicherlich auch Gudula Linck im Visier gehabt, die ausgehend von seiner Lehre des Leibes die chinesische Kulturgeschichte und Medizin durchleuchtete, z. B. in Yin und Yang - Die Suche nach Ganzheit im chinesischen Denken, Leib oder Körper - Mensch, Welt und Leben in der chinesischen Philosophie, Poesie des Alterns - Chinesische Philosophie und Lebenskunst. Wir sind glücklich, Frau Prof. Gudula Linck für den Nachruf des für eine ganzheitliche Medizin so wichtigen Mannes gewonnen zu haben. Unnötig zu sagen, dass sie mehrere Male DZA-Autorin und Vortragende bei Gesellschaften für Akupunktur, TCM und Qigong war. 